\title{
A pilot study of road lighting, cycle lighting and obstacle detection
}

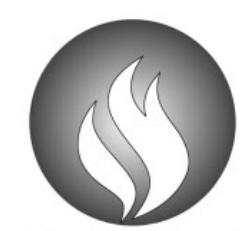

The Society of Light and Lighting

\author{
S Fotios PhD, H Qasem BArch, C Cheal PhD and J Uttley BSc \\ School of Architecture, University of Sheffield, Sheffield, UK
}

Received 30 September 2015; Revised 26 November 2015; Accepted 9 December 2015

This paper investigates cyclists' detection of an obstacle on the surface of the road ahead, observed in peripheral vision, and how this is affected by variations in light level from road and cycle lighting. The data analysed were the height at which a rising obstacle was detected, this simulating an approaching irregularity in the road surface. The results suggest that when cycling on a lit road, cycle lighting frequently offers no benefit for peripheral detection and may make it worse. It was demonstrated that position matters: At low illuminances, a hub-mounted lamp improved detection over a handlebar-mounted lamp. This benefit was sufficient to offset the reduction in detection found when decreasing road lighting from 2.0 lux to 0.2 lux.

\section{Introduction}

Obstacle detection is a critical visual task for pedestrians ${ }^{1-3}$ and we suspect it is a critical task also for cyclists. Road lighting must provide for adequate obstacle detection as a countermeasure to cycling accidents in addition to enhancing the visibility of cyclists to other road users. ${ }^{4}$ Potential obstacles include uneven surfaces (e.g. a raised paving slab or manhole cover, potholes) and objects on the road that may cause a cyclist to fall from their bicycle or to suddenly swerve to avoid the obstacle if not anticipated in sufficient time to take safe avoiding action. Because cyclists are located on the road adjacent to motor vehicles, the consequences of falling or swerving are likely to be more serious than for pedestrians on the footpath.

Before investigating the effect of changes in lighting on cyclists' visual needs, it would be useful to study what it is they desire look at for safe movement - for example by using

Address for correspondence: S Fotios, School of Architecture, The University of Sheffield, Arts Tower, Western Bank, Sheffield S10 2TN, UK.

E-mail: steve.fotios@sheffield.ac.uk eye-tracking. This was recently done for pedestrians, using a dual task to identify fixations at critical moments ${ }^{2}$ and to estimate the distance and duration for which pedestrians desire to carry out these fixations. ${ }^{5}$ Eye tracking studies used to investigate cyclists' visual behaviour have tended to use artificial settings such as watching a video ${ }^{6}$ and artificial, straight lanes marked out in a gymnasium. ${ }^{7}$ For pedestrians, natural settings and videos lead to different gaze allocation ${ }^{8}$ and the same is expected for cyclists. Vansteenkiste et al. ${ }^{9}$ studied the visual gaze behaviour of five cyclists along a city centre route and found a greater proportion of gazes were toward the road surface when the surface quality was low than when it was high, suggesting that detection of potential obstacles was an important task. However, they did not employ a dual task or similar to distinguish critical fixations from all gaze fixations. Thus, there are currently insufficient data regarding the visual fixations of cyclists in natural settings.

This paper reports three pilot studies carried out to explore how road lighting and bicycle-mounted lighting affect the ability to detect an obstacle located ahead but in 
peripheral vision. We anticipate this is a critical visual task for cyclists but that remains to be confirmed. We investigated detection in peripheral vision ${ }^{10}$ where the capability of the eye is mainly determined by contrast sensitivity. ${ }^{11}$ The contrast between the luminance of the sides of a raised obstacle and that of the top surface and the surrounding floor surface will vary with the direction of light. For cyclists, this light may come from two sources - the road lighting and cycle-mounted lighting. This work considered three levels (illuminances) of road lighting but did not consider the spectral power distribution (SPD) or the uniformity of this lighting. It also considered cycle lighting of different luminance and mounting position. In Experiment 1, we investigated obstacle detection using a handlebar mounted lamp at three luminances. In Experiment 2, the cycle lamp was set to only one luminance, the middle of the three used in Experiment 1, but was located at three vertical heights equivalent to the cyclist's helmet, the handlebars and the wheel hub. These results suggested a benefit of hub-mounted lighting and hence in Experiment 3, we repeated Experiment 1 but with the cycle lamp mounted at the wheel hub.
We first report below the apparatus and the general method used in the three experiments, and then the conditions and results of the three experiments in turn.

\section{Method}

\subsection{Apparatus}

Obstacle detection was tested using the apparatus shown in Figure 1 which was previously used to investigate obstacle detection for pedestrians. ${ }^{12}$ It is a chamber that is open on one side - where the participant was located - and lit from two overhead arrays of LEDs. The chamber has a raised floor containing cylinders which can be raised above the surface using electric motors to simulate obstacles. The chamber is of dimensions $2.4 \mathrm{~m}$ wide, $2.4 \mathrm{~m}$ high and $3.8 \mathrm{~m}$ long, with walls covered in black cotton cloth on three of the sides and open at the fourth side. The false floor was made from medium density fibre board and painted in Munsell N5 grey paint (reflectance $=0.2$ ).

A static bicycle was placed at the open end of the chamber and during trials participants sat upon this cycle to replicate the head and

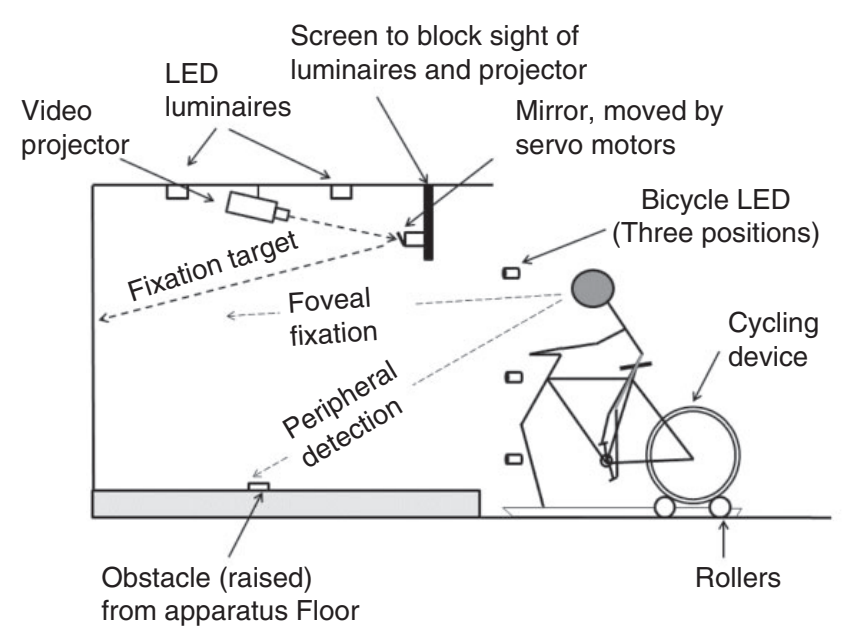

Figure 1 Section (left) and plan (right) of apparatus.

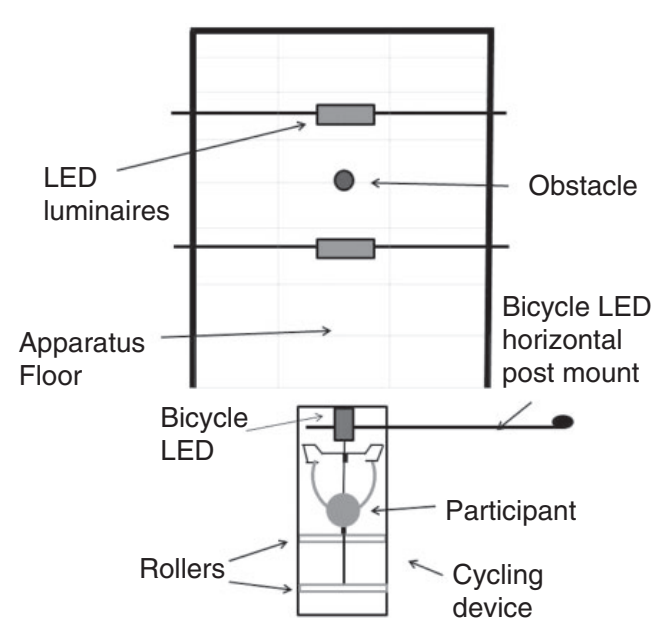

Lighting Res. Technol. 2017; 49: 586-602 
eye posture of a cyclist. To allow pedalling the bicycle was mounted on rollers, but for safety it was held upright using a frame. During trials, participants were instructed to pedal to simulate the cognitive demand of pedalling. To encourage pedalling at a reasonable speed, an alarm sounded if the rotational speed dropped below 50 revolutions per minute or above 80 revolutions per minute.

This experiment used one obstacle cylinder located at the centre of the false floor, $200 \mathrm{~mm}$ in diameter. This was normally flush with the surrounding floor but could be raised to one of seven heights $(0.5 \mathrm{~mm}, 2.8 \mathrm{~mm}, 4.5 \mathrm{~mm}, 7.1 \mathrm{~mm}$, $11.3 \mathrm{~mm}, 17.9 \mathrm{~mm}$ and $28.4 \mathrm{~mm}$ ) to simulate an obstacle. The smallest height $(0.5 \mathrm{~mm})$ was used as a control condition as it was a height for which the detection probability was expected to approach zero. This was done in order to check for false positive responses. The sides and top of the obstacle were painted in the same grey paint as used for the rest of the surrounding surfaces. The centre of the obstacle was positioned $1.2 \mathrm{~m}$ from the far wall and approximately $2.6 \mathrm{~m}$ from the participant's position on the cycle, giving an eye to obstacle distance of approximately $3 \mathrm{~m}$. At this distance and for an eye level of $1.75 \mathrm{~m}$, the obstacle subtended a width of $3.65^{\circ}$ and height of $0.43^{\circ}$ at the participant's eyes at the maximum height used in this experiment $(28.4 \mathrm{~mm})$. Each of the seven obstacle heights was presented at two rising speeds $(1.0 \mathrm{~mm} / \mathrm{s}$ and $2.0 \mathrm{~mm} / \mathrm{s}$ ) giving 14 trials per lighting condition. The order in which these 14 trials took place was randomised for each lighting condition. Following analysis in previous work $^{12}$ of the effect of obstacle rising speed, the current analysis used the average response across the two rising speeds.

Participants indicated detection by pressing a hand-held response button. If detection occurred before the obstacle reached its maximum height, it would immediately return to lie flush with the surrounding surface, the home position, and a successful detection would be recorded. If the obstacle reached its maximum height without the button being pressed, it would remain at this height for $2 \mathrm{~s}$, or until the button was pressed (whichever was sooner), before returning to the home position. If the button was pressed within this $2 \mathrm{~s}$ period, a detection was recorded, but if not a miss was recorded. For the control condition $(0.5 \mathrm{~mm}$ obstacle height $)$, the exposure time at maximum height was increased to $8 \mathrm{~s}$, this representing the typical average time of other trials, including random time interval and time to reach and remain at the maximum height. The $8 \mathrm{~s}$ control condition would capture false positive responses from guessing or pressing the response button randomly.

A dynamic fixation mark was projected onto the rear wall of the test room by reflection from a gimbal-mounted mirror. By dynamic, we mean that the location of the fixation mark moved (by operation of the mirror gimbal), and the fixation mark changed at random intervals from a crosshair (the normal status) to a digit (1 to 9) at random intervals between $2 \mathrm{~s}$ and $6 \mathrm{~s}$ for $0.2 \mathrm{~s}$ before returning to the crosshair. Participants were instructed to read aloud these numbers, this response being recorded and used as a measure of fixation maintenance. The fixation mark moved randomly within an ellipse on the far wall, this ellipse having a height of $1.05 \mathrm{~m}$ and width of $2 \mathrm{~m}\left(15.7^{\circ} \times 29.5^{\circ}\right)$ with its centre $1.5 \mathrm{~m}$ above the false floor. The maximum possible visual angle between the fixation target and the obstacle was $41.4^{\circ}$ (when the fixation mark was at the top of the ellipse), the minimum $18.6^{\circ}$ (when the fixation mark was at the bottom of the ellipse). Lowreflectance black screening was placed around the mirror so that only the light falling on the mirror was reflected back on to the far wall, thus reducing any confounding effects of light from the projector. Many peripheral detection studies employ a static fixation mark and there has been little - if any - validation of the degree to which fixation was maintained. The purpose of this dynamic fixation target was to 
maintain foveal fixation on the fixation mark, thereby better ensuring peripheral vision was used for the obstacle detection task. ${ }^{13}$

The test area was lit from above by two identical arrays of LEDs as shown in Figure 1, simulating overhead road lighting. Each LED array contained six clusters of four types of LED, red, green, blue and amber. The control system allowed the intensity of each type of LED to be independently modulated, thus allowing a wide range of unique spectra to be set. The illuminance provided by these arrays was varied but only one SPD was used $(\mathrm{S} / \mathrm{P}=1.6, \mathrm{x}=0.46, \mathrm{y}=0.42)$. The SPD is shown in Figure 2. Tests were carried out under three horizontal illuminances, 0.2 lux, 2.0 lux and 20.0lux, as measured at the centre of the obstacle, and a fourth condition in which the LED array was switched off. These illuminances bracket the illuminances recommended in UK road lighting guidelines ${ }^{14}$ and follow those used in previous peripheral detection studies ${ }^{12,15,16}$ to enable comparison.

A second light source simulated a forwardfacing bicycle-mounted lamp (LED Lenser model H14R.2). The bicycle lamp introduces many additional variables: mounting location on the bicycle, beam angle and direction, luminance and SPD, and careful consideration

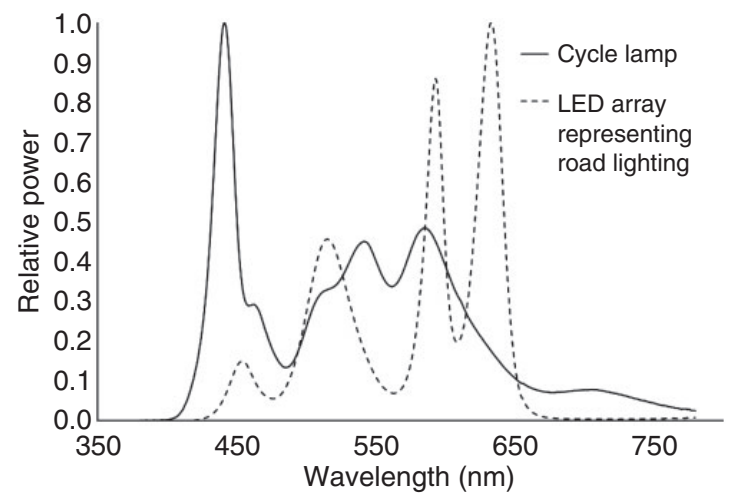

Figure 2 Spectral power distributions (normalised to a peak response of unity) for the LED array simulating overhead road lighting and for the cycle-mounted lamp of these may lead to improved lamp design. ${ }^{17}$ In this experiment, we investigated two variables - mounting height and luminance. The three mounting positions were the wheel hub, handlebar or cyclists' helmet, these giving heights above ground level as shown in Table 1. These positions were in a single vertical line, $1370 \mathrm{~mm}$ from the obstacle centre, at the centre line of the bicycle. At the three locations, the lamp was aimed so that the obstacle was approximately in the centre of the beam, with the leading edge at the same position. The beam patterns are shown in Figure 3. For luminance, the lamp was either switched off or set to $0.1 \mathrm{~cd} / \mathrm{m}^{2}, 0.32 \mathrm{~cd} / \mathrm{m}^{2}$ and $1.0 \mathrm{~cd} / \mathrm{m}^{2}$ as measured on the side of the raised obstacle facing the observer. This dimming was achieved using the lamp's built-in control, with a neutral density filter (25\% light transmission) placed directly in front of the lamp at all times to reduce its light output. A fibre optic cable located in the periphery of the beam, light sensor (TSL2591 and Arduino microcontroller) allowed accurate adjustment to predetermined intensities and corresponding to luminances of the obstacle side, and monitoring/logging of the intensity during trials. The SPD is shown in Figure 2. The cycle lamp spectrum had a correlated colour temperature of $6500 \mathrm{~K}$, a general colour rendering index of $\mathrm{R}_{\mathrm{a}}=75$ and a $\mathrm{S} / \mathrm{P}$ ratio of 2.1. Tables A1 to A3 in Appendix A show luminances measured on the top and front surfaces of the raised obstacle and of the floor immediately in front of the obstacle - for all test conditions.

In this work, illuminance is used to quantify the amount of road lighting since illuminance

Table 1 Description of mounting positions of the bicycle lamp

\begin{tabular}{lll}
\hline Location & $\begin{array}{l}\text { Height of lamp } \\
\text { above floor }(\mathrm{mm})\end{array}$ & Beam direction \\
\hline Handlebar & 1370 & $20^{\circ}$ below horizontal \\
Helmet & 1830 & $35^{\circ}$ below horizontal \\
Hub & 565 & Horizontal \\
\hline
\end{tabular}


is the quantity specified in guidance. ${ }^{14}$ Luminance is used to describe the amount of light from the cycle lamp to assist recognition of which light source is being referred to.

Three experiments were carried out, each using 10 participants, and these were paid a small fee as an incentive. The 30 test participants included 12 males, 18 females, and their ages ranged from 18 to 36 years with an overall estimated mean age of 26 years; 13 participants wore their normal corrective lenses.

\subsection{Procedure}

Initially, normal vision was confirmed using a Landolt ring acuity chart and the Ishihara test for colour blindness. A 20-minute period allowed for dark adaptation; during this time, the test procedure was explained and participants were given time to become accustomed to pedalling the bicycle.

A practice session was included to introduce the fixation task and the obstacle detection task (pressing the response button if they noticed a raised obstacle). This practice session introduced progressive levels of difficulty to the tasks to ensure participants became used to them and were able to complete them satisfactorily. For instance, the fixation target was static to begin with and positioned at the narrowest vertical visual angle with the obstacle.

In trials, participants were instructed to fixate upon the fixation target, stating aloud any digits that appeared, whilst pedalling and pressing the response button if they detected a raised obstacle. To encourage participants to maintain foveal gaze on the moving fixation target, the experimenter stated that the fixation target task should be their primary focus.

For each lighting condition, a period of approximately 3 minutes was required to complete the 14 detection trials. If the participant requested a break or if four consecutive conditions had been completed, a short rest period was taken (approximately $3 \mathrm{~min}$ utes to 4 minutes) until the participant was ready to resume.

Experiment 1 examined variations in road lighting and cycle lighting luminances but the cycle light was retained in only one position, mounted on the handlebar, this being a common location for bicycle lamps. The 10 test participants (six male, four female, aged 18 years to 36 years, mean 27 years, four wore corrective lenses), each completed trials under the 16 conditions (four road lighting illuminances, four bicycle light luminances) in a random order within a single 2-hour test session.

Experiment 2 examined the effect of varying the location of the cycle lamp (change in vertical height) and did so with only one bicycle light luminance $-0.32 \mathrm{~cd} / \mathrm{m}^{2}-$ the middle of the three settings used in Experiment 1. The four road lighting illuminances were retained (off, 0.2 lux, 2.0 lux and $20 \operatorname{lux})$. The three vertical positions of the
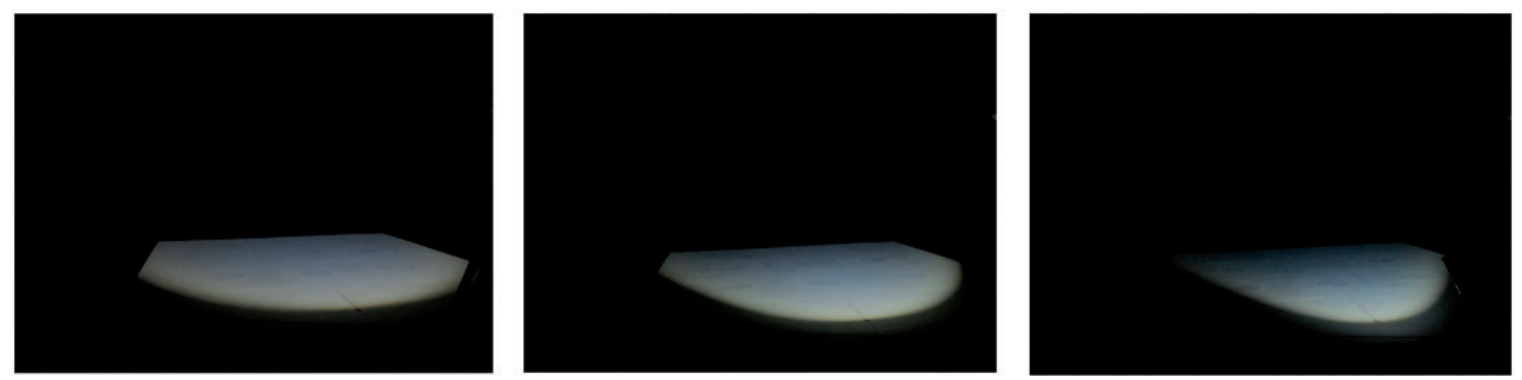

Figure 3 Beam pattern on the floor surface ahead of the cyclists when the cycle-mounted lamp was located at the helmet (left), handlebar (middle) and wheel hub (right) 
cycle lamp were equivalent to the cyclist's helmet - the handlebars and the wheel hub. The 10 test participants (two male, eight female; aged 19 to 36 years, mean age 27 years, three wore corrective lenses), each completed trials under all 12 conditions in a random order.

The results of Experiments 1 and 2 were analysed to devise a hypothesis to be tested in Experiment 3. Initially, a small number of conditions were chosen to confirm the apparent benefit of the hub-mounted bicycle lamp over a handlebar or helmet mounted lamp in terms of increasing obstacle detection rate with further conditions included to replicate for internal validation conditions used in Experiments 1 and 2. These conditions fell into a repeat of Experiment 1 but with the bicycle lamp mounted on the wheel hub rather than the handlebar and hence this is what was done. Thus, Experiment 3 examined variations in road lighting and cycle lighting luminances with the cycle light mounted on the wheel hub. The 10 test participants (four male, six female; aged 18 to 35 years, mean 24 years, six wore corrective lenses), each carried out trials under all 16 conditions (four LED illuminances, four bicycle light luminance) in a random order.

\section{Results}

\subsection{Fixation target identification}

The fixation cross changed to a number at random intervals during trials, and in each test condition, this occurred 40 times on average. Test participants were required to read aloud these numbers to provide a measure of their focus on the fixation target. The overall rate of correct identification across all experiments was $88 \%$ (standard deviation 4.2 $\%$ ), this being $91 \%, 90 \%$ and $84 \%$ in Experiments 1, 2 and 3, respectively. We conclude from this that participants were tending to direct their gaze towards the fixation mark as instructed and thus that the obstacle tended to lie in peripheral vision.

\subsection{Validation conditions}

Two conditions were included to provide some measure of validation. These were nolight trials, i.e. tests carried out in the absence of road and cycle lighting (Experiments 1 and 3) and trials in all conditions with the smallest $(0.5 \mathrm{~mm})$ obstacle: In both cases, a low rate of detection is expected and a high detection rate would indicate false positives (e.g. random pressing of the detection button).

Table 2 Summary of results of validation conditions

\begin{tabular}{|c|c|c|c|c|c|c|}
\hline \multirow[t]{2}{*}{ Exp. no. } & \multicolumn{2}{|l|}{ No-light trials } & \multicolumn{2}{|l|}{0.2 lux trials } & \multicolumn{2}{|c|}{ Detection rate ${ }^{* * *}$} \\
\hline & $\begin{array}{l}\text { Detection } \\
\text { rate* }\end{array}$ & $\begin{array}{l}\text { Detection } \\
\text { height }^{* *}\end{array}$ & $\begin{array}{l}\text { Detection } \\
\text { rate* }\end{array}$ & $\begin{array}{l}\text { Detection } \\
\text { height** }\end{array}$ & $\begin{array}{l}0.5 \mathrm{~mm} \\
\text { obstacle }\end{array}$ & $\begin{array}{l}2.8 \mathrm{~mm} \\
\text { obstacle }\end{array}$ \\
\hline 1 & $\begin{array}{l}0.043 \\
(6 / 140 \text { trials })\end{array}$ & $\begin{array}{l}25.1 \mathrm{~mm} \\
\text { (range } 20.6 \\
\text { to } 26.0 \mathrm{~mm}, \mathrm{n}=4 \text { ) }\end{array}$ & $\begin{array}{l}0.51 \\
(71 / 140 \text { trials })\end{array}$ & $\begin{array}{l}6.65 \mathrm{~mm} \\
\text { (range } 5.0 \\
\text { to } 11.2 \mathrm{~mm}, \mathrm{n}=16 \text { ) }\end{array}$ & $\begin{array}{l}0.12 \\
(37 / 300 \text { trials })\end{array}$ & $\begin{array}{l}0.36 \\
(108 / 300 \text { trials })\end{array}$ \\
\hline 2 & - & - & - & - & $\begin{array}{l}0.18 \\
(44 / 240 \text { trials })\end{array}$ & $\begin{array}{l}0.45 \\
(109 / 240 \text { trials })\end{array}$ \\
\hline 3 & $\begin{array}{l}0.10 \\
(14 / 140 \text { trials })\end{array}$ & $\begin{array}{l}22.3 \mathrm{~mm} \\
\text { (range } 18.4 \mathrm{~mm} \\
\text { to } 28.4 \mathrm{~mm}, \mathrm{n}=8 \text { ) }\end{array}$ & $\begin{array}{l}0.69 \\
(97 / 140 \text { trials })\end{array}$ & $\begin{array}{l}5.32 \mathrm{~mm} \\
\text { (range } 2.8 \\
\text { to } 14.4 \mathrm{~mm}, \mathrm{n}=20 \text { ) }\end{array}$ & $\begin{array}{l}0.18 \\
(54 / 300 \text { trials })\end{array}$ & $\begin{array}{l}0.69 \\
(208 / 300 \text { trials })\end{array}$ \\
\hline
\end{tabular}

*Detection rate: Proportion of trials with all seven obstacle heights that were detected.

**Detection height: median height (range and number of detections) at which the 28.4 mm obstacle was detected.

***Detection rate for $0.5 \mathrm{~mm}$ and $2.8 \mathrm{~mm}$ obstacles: this includes trials in all lighting conditions but excludes no-light trials in Experiments 1 and 3. 
The results of these trials are shown in Table 2. For the no-light trials, detection probability was 0.07 across Experiments 1 and 3 and the $28.4 \mathrm{~mm}$ obstacle needed to reach a median height of over $22 \mathrm{~mm}$ to be detected. For comparison, Table 2 shows also the results of trials when the road lighting was set to its lowest level - 0.2lux: The detection probability increased to 0.6 and the median detection height of the $28.4 \mathrm{~mm}$ obstacle decreased to approximately $6 \mathrm{~mm}$. The large difference in detection responses between these two conditions suggests that test participants did not tend to make false alarm responses. That in a very small number of trials, test participants were able to detect a target during these no-light trials suggests the presence of some stray light - for example scattered light from the projected fixation mark.

Detection probability for the $0.5 \mathrm{~mm}$ obstacle height was expected to be much lower than for the higher obstacle heights. The $0.5 \mathrm{~mm}$ obstacle was detected in 135 of the 840 occasions it was presented across the three experiments - a detection probability of 0.16 . Compared with the next smallest obstacle in the range $(2.8 \mathrm{~mm})$ which had an overall detection probability of 0.51 across the three experiments, the $0.5 \mathrm{~mm}$ target was detected on relatively few occasions - again suggesting that test participants did not tend to make false alarm responses.

\subsection{Experiment 1}

Experiment 1 examined 16 light combinations (four LED illuminances, four bicycle light luminances) - with the bicycle lamp at the handlebar position. There are two approaches to examining the results, the detection probability for obstacles of different size and the height at which the largest obstacle $(28.4 \mathrm{~mm})$ was detected (detection height). In previous work, it was demonstrated that the results from both approaches converged. ${ }^{12}$ Therefore, we use here only the height at which the largest obstacle was detected as the measure of detection ability.

Analysis of normality was carried out using a range of statistical and graphical measures (central tendency, distribution, KolmogorovSmirnov and Shapiro-Wilks). It was concluded that these data (and also for Experiments 2 and 3) were not drawn from a normally distributed population. Statistical analyses were therefore carried out using non-parametric statistical tests for repeated measures data.

Figure 4 and Table 3 show the median detection height for each test condition. Consider the curve for road lighting only (i.e. cycle lamp switched off): this shows that higher illuminance allows smaller obstacles to be seen and displays a trend similar to that found in previous work..$^{12,15,16}$ At all three illuminances, there is no benefit in switching on the cycle lamp - obstacle detection was not improved. At low road light illuminance, there is a clear difference between the three cycle light luminances, but at high road light illuminance, this difference disappears. For the lowest cycle light luminance, there is a steady improvement in obstacle detection as road light illuminance increases. However, for the two higher cycle light luminances, obstacle detection first decreases and then increases - indicating that contrast reversal has affected detection.

Here we analyse the data for 15 of the 16 test conditions, i.e. ignoring results from those trials with no road or cycle lighting. Using the Friedman test to compare these 15 conditions suggests that changes in road and cycle lighting had a significant effect $(p<0.001)$. For analyses where multiple application of statistical testing was used, we retained the standard threshold of $p \leq 0.05$ to indicate significant effects and did not make adjustments to this ${ }^{18}$ but instead drew conclusions as to significance by considering the overall pattern of results rather than placing emphasis on any single test.

With the cycle lamp switched off, increases in road illuminance from 0.2 lux to a higher 


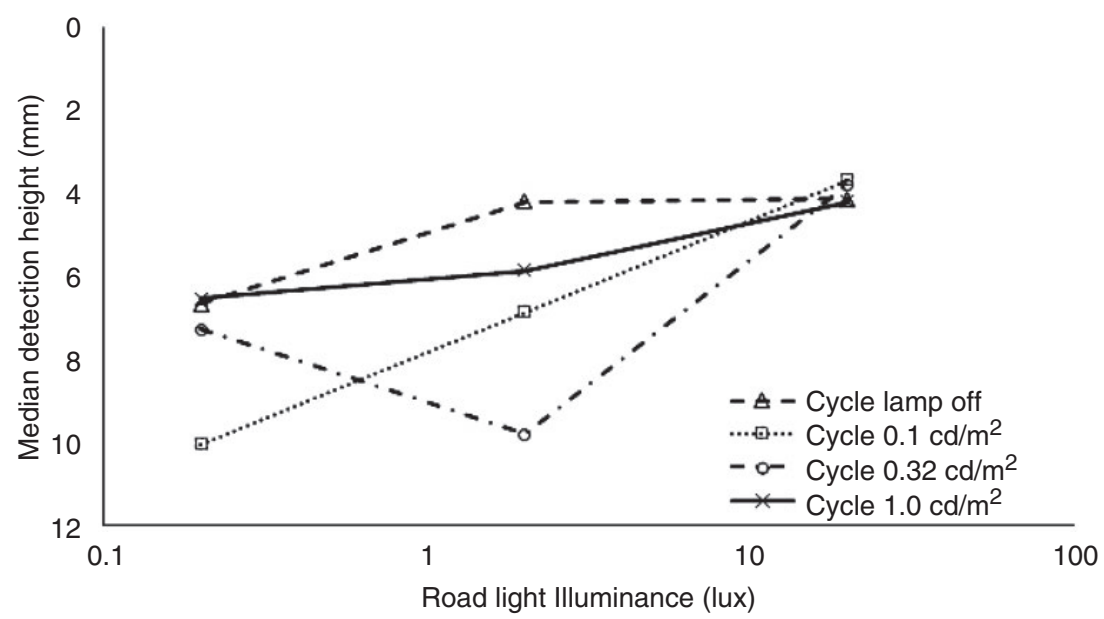

Figure 4 Results of Experiment 1: Median detection height (for $28.4 \mathrm{~mm}$ height) plotted against illuminance for four cycle lamp conditions. The bicycle light was located on the handlebar for all trials

Table 3 Results of Experiment 1: Median detection height (for $28.4 \mathrm{~mm}$ obstacle) for each combination of road light illuminance and cycle light luminance.

\begin{tabular}{lcccc}
\hline $\begin{array}{l}\text { Road LED } \\
\text { illuminance (lux) }\end{array}$ & $\begin{array}{l}\text { Detection height }(\mathrm{mm}) \text { of } \\
28.4(\mathrm{~mm}) \text { obstacle height } \\
\text { under the given bicycle } \\
\text { light luminance }\end{array}$ \\
\cline { 2 - 5 } & 0 & $0.1 \mathrm{~cd} / \mathrm{m}^{2}$ & $0.32 \mathrm{~cd} / \mathrm{m}^{2}$ & $1.0 \mathrm{~cd} / \mathrm{m}^{2}$ \\
\hline 0 & 25.1 & 7.12 & 7.02 & 5.25 \\
0.2 & 6.65 & 10.0 & 7.28 & 6.52 \\
2 & 4.20 & 6.85 & 9.80 & 5.85 \\
20 & 4.12 & 3.68 & 3.78 & 4.20 \\
\hline
\end{tabular}

The bicycle light was located on the handlebar for all trials.

level give a significant increase in detection $(p<0.05)$ but an increase above 2.0 lux does not have significant effect. Switching on the cycle lamp did not increase detection, regardless of the luminance it was set to. With 2.0 lux road lighting, the addition of cycle lighting of any luminance significantly decreased detection performance $(p<0.05)$. At 0.2 lux and 20 lux, adding cycle lighting either makes no significant difference or leads to a significant decrease.

\subsection{Experiment 2}

Experiment 2 examined 12 lighting combinations comprising four road lighting illuminances, one bicycle light luminance $\left(0.32 \mathrm{~cd} / \mathrm{m}^{2}\right)$ and three cycle light positions resembling the helmet, handlebar and hub positions on a bicycle. The aim of this experiment was to determine whether the mounting position of a given cycle lamp would affect detection. The results are shown in Figure 5 and Table 4.

Figure 5 suggests that at lower road lighting, illuminances detection is best for the hubmounted cycle lamp and poorest for the helmet-mounted lamp. At the highest road light levels, this difference disappears. The Friedman test suggests that mounting positon has a significant effect $(p<0.01)$ for two cases, when the road lighting is switched off or set to the lower illuminance (0.2 lux), but does not suggest a significant effect at the higher illuminances (2.0 lux, 20lux). This conclusion is confirmed using the Wilcoxon test for each pair of possible mounting locations. At zero or 0.2 lux, detection is best for the hub-mounted lamp and poorest for the helmet-mounted lamp. At 2.0lux and 20lux, a change in 


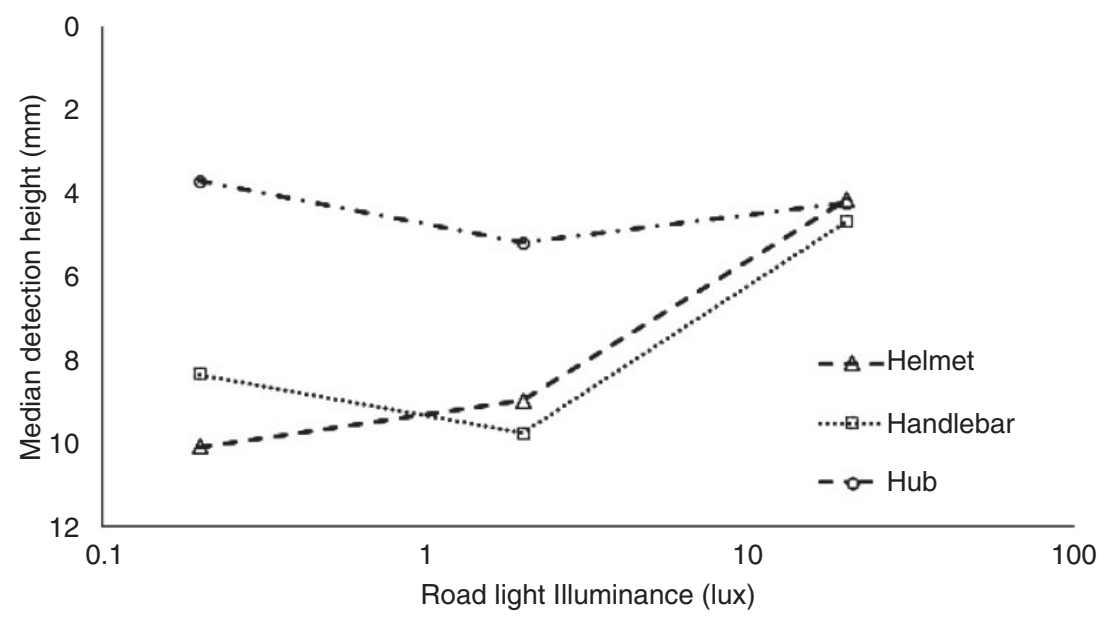

Figure 5 Results of Experiment 2: Median detection height (for $28.4 \mathrm{~mm}$ height) plotted against illuminance when the cycle lamp was mounted on either the helmet, handlebar or wheel hub

Table 4 Results of Experiment 2: Median detection height (for $28.4 \mathrm{~mm}$ obstacle) for each combination of road light illuminance and cycle light location.

\begin{tabular}{llll}
\hline $\begin{array}{l}\text { Road LED } \\
\text { illuminance (lux) }\end{array}$ & \multicolumn{3}{l}{$\begin{array}{l}\text { Detection height (mm) of } \\
28.4(\mathrm{~mm}) \\
\text { the given bicycle light location }\end{array}$} \\
\cline { 2 - 4 } & Helmet & Handlebar & Hub \\
\hline 0 & 12.5 & 6.3 & 3.32 \\
0.2 & 10.1 & 8.35 & 3.7 \\
2.0 & 8.98 & 9.78 & 5.18 \\
20 & 4.12 & 4.65 & 4.22 \\
\hline
\end{tabular}

The bicycle light was set to provide a target luminance of $0.32 \mathrm{~cd} / \mathrm{m}^{2}$ for all trials.

mounting position of the cycle lamp did not affect detection.

\subsection{Experiment 3}

Experiment 3 examined 16 lighting combinations (four LED road lighting illuminances and four bicycle light luminances) - the same conditions as for Experiment 1 - but with the cycle lamp mounted at a lower vertical position, the wheel hub rather than the handlebar. The results are shown in Figure 6 and Table 5.
The road-lighting-only curve again displays a trend similar to that of Experiment 1 (Figure 4) and as found in previous work. $^{12,15,16}$ Increasing the road illuminance from 0.2 lux to 20 lux did significantly increase detection $(p<0.01)$ but increases from 0.2 lux to 2.0 lux or from 2.0 lux to 20 lux were not suggested to be significant.

In contrast to Experiment 1, switching on the hub-mounted cycle lamp could lead to significant increase in detection performance, although only at $0.2 \operatorname{lux}(p<0.05)$. At 2.0 lux, switching on cycle lighting to $0.1 \mathrm{~cd} / \mathrm{m}^{2}$ or $0.32 \mathrm{~cd} / \mathrm{m}^{2}$ led to a significant decrease in detection performance but had no effect at $1.0 \mathrm{~cd} / \mathrm{m}^{2}$. At 20 lux, switching on cycle lighting to any luminance led to a significant decrease in detection. Note also that at 0.2 lux, the luminance of the cycle lamp did not have significant effect.

The curves for the individual cycle lamp luminances suggest an effect of contrast reversal as the road illuminance varies. The two lower luminances $\left(0.1 \mathrm{~cd} / \mathrm{m}^{2}\right.$ and $0.32 \mathrm{~cd} /$ $\mathrm{m}^{2}$ ) follow the same pattern, with a significant decrease $(p<0.05)$ in detection ability, when increasing road lighting from 0.2 lux to 2.0 lux 


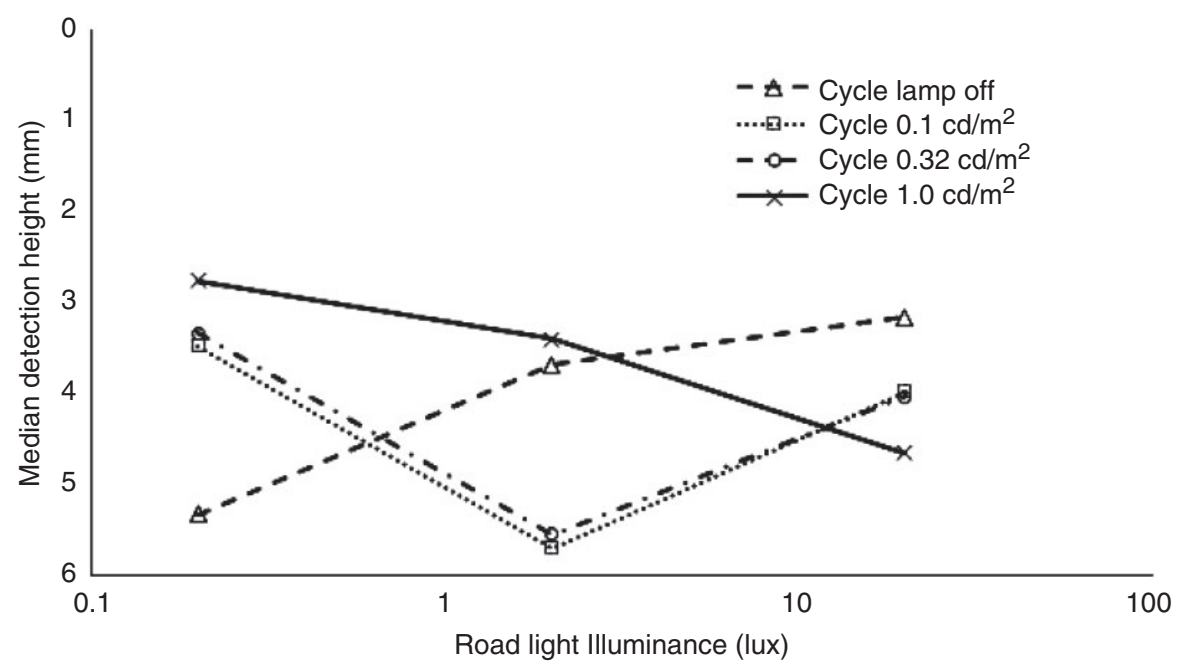

Figure 6 Results of Experiment 3: Median detection height (for $28.4 \mathrm{~mm}$ height) plotted against illuminance. The bicycle light was located on the hub for all trials

Table 5 Results of Experiment 3: Median detection height (for $28.4 \mathrm{~mm}$ obstacle) for each combination of road light illuminance and cycle light luminance.

\begin{tabular}{lcccc}
\hline $\begin{array}{l}\text { Road LED } \\
\text { illuminance } \\
\text { (lux) }\end{array}$ & $\begin{array}{l}\text { Detection height }(\mathrm{mm}) \text { of } \\
28.4(\mathrm{~mm}) \text { obstacle height } \\
\text { under the given bicycle } \\
\text { lamp luminance }\end{array}$ \\
\cline { 2 - 5 } & 0 & $0.1 \mathrm{~cd} / \mathrm{m}^{2}$ & $0.32 \mathrm{~cd} / \mathrm{m}^{2}$ & $1.0 \mathrm{~cd} / \mathrm{m}^{2}$ \\
\hline 0 & 22.3 & 3.52 & 3.20 & 3.30 \\
0.2 & 5.32 & 3.48 & 3.32 & 2.75 \\
2 & 3.68 & 5.70 & 5.55 & 3.40 \\
20 & 3.15 & 3.98 & 4.02 & 4.65 \\
\hline
\end{tabular}

The bicycle light was located on the wheel hub for all trials.

followed by an increase in detection ability when increasing from 2.0 lux to 20 lux, although this latter change is not suggested to be significant. This is a similar trend to that exhibited by the handlebar-mounted lamp at $0.32 \mathrm{~cd} / \mathrm{m}^{2}$ in Experiment 1 (Figure 4) and Experiment 2 (Figure 5). For the higher luminance $\left(1.0 \mathrm{~cd} / \mathrm{m}^{2}\right)$, there is a gradual reduction in detection ability as road lighting illuminance increases, but this is suggested to be significant only when changing from 0.2 lux to 2.0 lux.
Comparing results of Experiments 1 and 3 for those conditions with the cycle lamp switched on enables a comparison of the hub and handlebar mounting positions (Figure 7). These data reinforce the advantage of the hub light at low road light illuminances. Results from the two experiments were compared using the Mann-Whitney test for unrelated samples. This suggested the hubmounted lamp gave significantly better detection $(p<0.001)$ than the handlebar-mounted lamp at 0.2 lux, for all three cycle lamp luminances: At 2.0 lux, the difference is significant $(p<0.05)$ for only the higher luminance $\left(1.0 \mathrm{~cd} / \mathrm{m}^{2}\right)$ but the difference is not suggested to be significant at 20 lux $(p>0.54)$.

\section{Discussion}

\subsection{Summary of findings}

Experiment 1 employed a handlebarmounted cycle lamp - the common mounting location - and found that switching on this lamp led either to reduced detection performance or had no effect. Experiment 2 suggested that mounting the cycle lamp at a lower vertical 


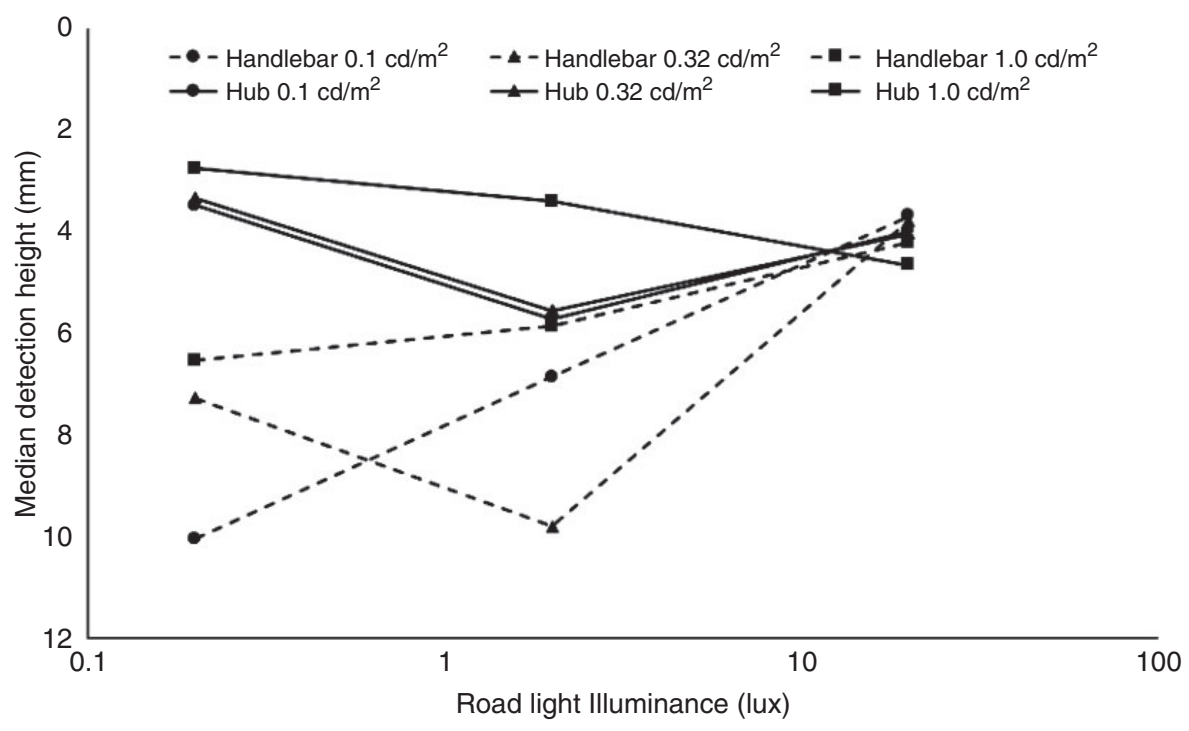

Figure 7 Median detection height (for $28.4 \mathrm{~mm}$ height) plotted against illuminance for the with-cycle-lighting conditions of Experiments 1 and 3 in which the cycle lamp was mounted on the handlebar and hub respectively

position - here being the hub of the front wheel - led to a significant increase in detection at low road light illuminance ( 0.2 lux) but this benefit was not apparent at higher illuminances. Experiment 3 confirmed that the hub-mounted lamp increased detection but only at 0.2lux, again with no advantage at 2.0 lux or 20 lux.

Regarding the hub-mounted lamp, Experiment 2 used only one cycle lamp luminance $-0.32 \mathrm{~cd} / \mathrm{m}^{2}$. The results of Experiment 3 show that the lower luminance $\left(0.1 \mathrm{~cd} / \mathrm{m}^{2}\right)$ provided similar detection performance. The advantage of the higher luminance $\left(1.0 \mathrm{~cd} / \mathrm{m}^{2}\right)$ was that it avoids the decrease in detection performance at 2.0 lux found with lower luminances but did not offer significant advantage over road lighting alone.

Regarding road lighting, the results of Experiments 1 and 3 suggest little benefit in providing an illuminance above 2.0 lux. If the road lighting illuminance is reduced from 2.0 to 0.2 lux, this leads to a reduction in detection performance, suggested to be a significant reduction in Experiment $1(p<0.05)$ but not suggested to be significant in Experiment 3.
This reduction in detection can be offset by cycle lighting if this is mounted on the hub but is not offset if the lamp is mounted on the handlebar or helmet.

The above analyses used detection height, the height at which the largest obstacle $(28.4 \mathrm{~mm})$ was detected to investigate the effect of changes in lighting. An alternative approach to comparing lighting conditions is to compare the obstacle height for $50 \%$ detection $\left(\mathrm{h}_{50}\right)$. This second approach was also considered during analyses and - as in previous work ${ }^{12}$ led toward the same conclusions regarding the relationship between cycle and road lighting. As an example, Figure 8 shows $h_{50}$ plotted against illuminance for Experiment 3 with the hubmounted cycle lamp. To illustrate the variance found in the detection height data, Figure 9 shows the interquartile ranges found in Experiment 2 with the handlebar and hubmounted cycle lamps.

\subsection{Internal validation by repetition}

Three pairs of identical conditions were examined independently in two 


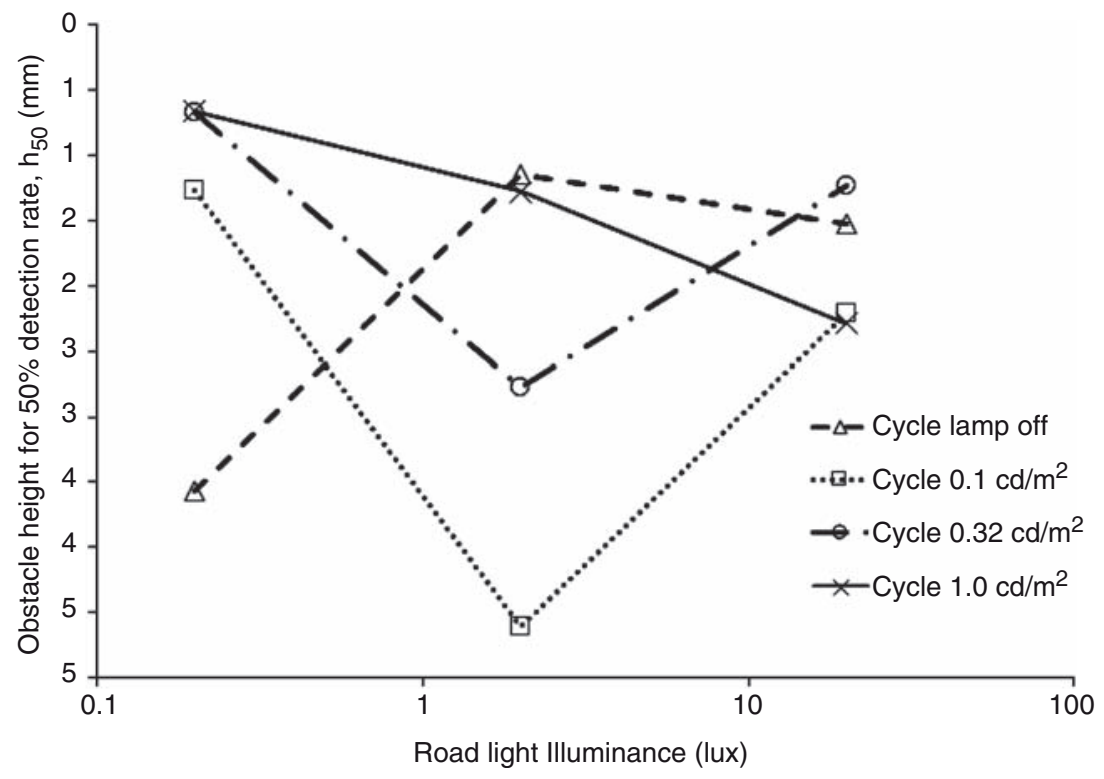

Figure 8 Results of Experiment 3: Obstacle height for $50 \%$ detection $\left(h_{50}\right)$ plotted against illuminance. The bicycle light was located on the hub for all trials

experiments - namely road light only (Experiments 1 and 3) - handlebar mounted cycle lamp set to $0.32 \mathrm{~cd} / \mathrm{m}^{2}$ (Experiments 1 and 2) and hub mounted cycle lamp set to $0.32 \mathrm{~cd} / \mathrm{m}^{2}$ (Experiments 2 and 3 ). The results of these conditions are shown in Figure 10. In each case, results from the two separate experiments tend to follow the same trend and this provides a measure of robustness. The Mann-Whitney test for independent samples did not suggest differences for identical conditions between experiments to be statistically significant.

\subsection{Contrast reversal}

In this experiment, the LED array (representing road lighting) lit the obstacle from above - creating a relatively bright top surface and surrounding surface compared with the side of the obstacle. The cycle lamp was projected toward the obstacle from the side and therefore created a brighter obstacle side than the surrounding horizontal surface. As the relative proportions of road

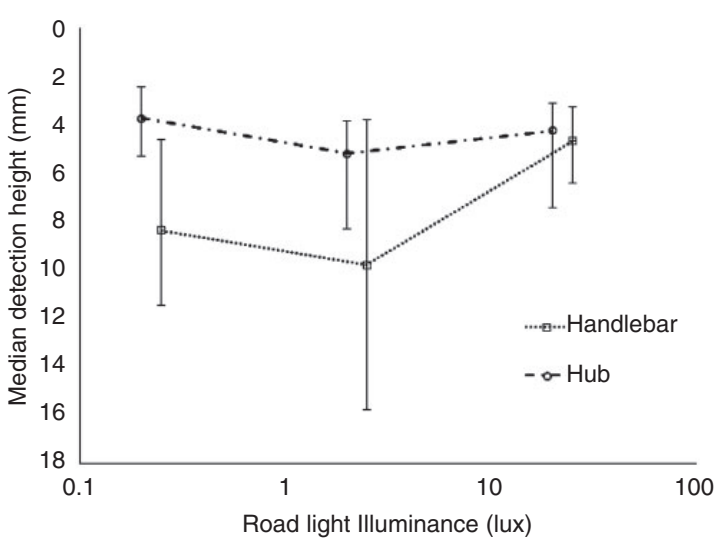

Figure 9 Results of Experiment 2: Median detection height (for $28.4 \mathrm{~mm}$ height) plotted against illuminance when the cycle lamp was mounted on either the handlebar or wheel hub. Error bars show interquartile range. For clarity, illuminances for the handlebar data have been shifted slightly to the right

and cycle light were changed, the relative contrast of the obstacle against the background (side versus surround) was also changed - with a larger contrast when either 


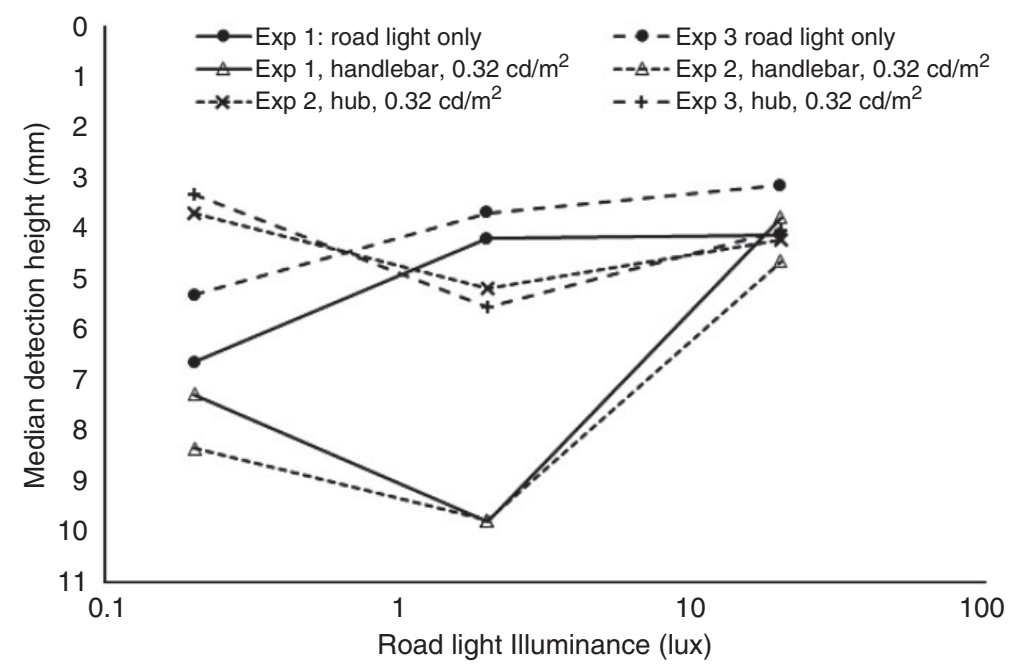

Figure 10 Comparison of median detection height for similar conditions carried out in separate experiments
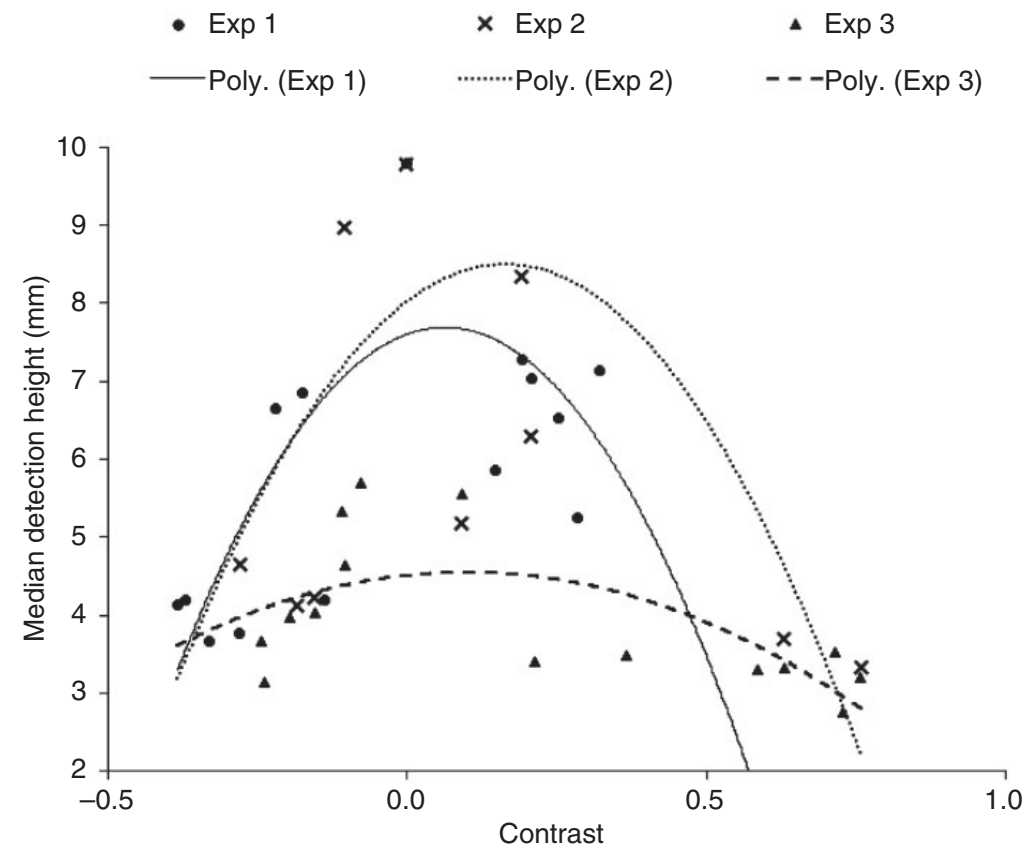

Figure 11 Median detection height $(\mathrm{mm})$ plotted against obstacle contras

road or cycle lighting were dominant and a smaller contrast (and hence reduced detection) when they presented luminances of similar magnitude.
This can be seen in Figure 11 in which detection height is plotted against obstacle contrast. Contrast was defined using Equation 1. Luminances were measured 
from the observation point with the obstacle luminance measured on the raised side of the obstacle and surround luminance measured immediately in front of the obstacle.

$$
\text { Contrast }=\left(\mathrm{L}_{\mathrm{O}}-\mathrm{L}_{\mathrm{S}}\right) / \mathrm{L}_{\mathrm{S}}
$$

where, $\mathrm{L}_{\mathrm{O}}=$ obstacle luminance

and $\mathrm{L}_{\mathrm{S}}=$ surround luminance

The relationship between detection height and contrast is approximately explained by a second order polynomial equation - with $\mathrm{R}^{2}$ values of $0.52,0.40$ and 0.42 for Experiments 1, 2 and 3 , respectively. These trend lines indicate the expected relationship between detection height and obstacle contrast - with better detection performance at higher contrast.

In Figure 11, a negative contrast means the surround is brighter than the side of the obstacle and vice-versa for positive contrast. For a given absolute contrast magnitude, a negative value of contrast permits detection of smaller obstacles, e.g. for the results of Experiment 1, a contrast of 0.25 requires a detection height of $7 \mathrm{~mm}$, but with a contrast of -0.25 , the detection height reduces to approximately $5.5 \mathrm{~mm}$, an improvement in detection performance. This suggests it is better to have a bright surround (obstacle seen in silhouette) than a bright obstacle - road lighting is more effective than cycle lighting.

We should also note that shadows may have affected obstacle detection. With the cycle light mounted in different locations, this would affect the length of shadow cast by the obstacle, being larger for the hub-mounted lamp (approximately $150 \mathrm{~mm}$ from far edge of obstacle to tip of shadow) and smaller for the helmet-mounted lamp (approximately $40 \mathrm{~mm}$ ). This may provide an alternative explanation as to why the hub lamp permits better detection than the handlebar and helmet positions.

\section{Conclusion}

This experiment explored obstacle detection for cyclists, investigating the relationship between lighting from overhead road lighting and a cycle-mounted lamp.

Detection under road lighting alone tended to follow the trend observed in previous work $^{12,15,16}$ with negligible reduction in detection when reducing illuminance from 20 lux to 2.0 lux, but a significant decrease in detection when reducing below 2.0 lux.

For the range of road lighting illuminances and cycle lamp luminances considered in the current study, it was found that - except for one case - the cycle lamp did not tend to enhance detection performance and could make detection worse through a reduction in obstacle-surround contrast. This case was for road lighting of low illuminance (0.2lux) when mounting the cycle lamp on the wheel hub improved detection compared with detection when mounted at the vertically higher and more common location of the handlebar. If road lighting was reduced from 2.0 lux to 0.2 lux, the reduction in detection can be offset by using a hub-mounted lamp.

A conclusion from these findings is that there is little benefit in using cycle lamps to aid obstacle detection when cycling along a lit road, so the cycle lamp characteristics should be chosen to aid the visibility of the cyclist to other road users rather than the cyclist's visual performance. An exception to this is using a hub-mounted lamp when the road lighting illuminance is low. Further, increasing the cycle-light luminance for a given road lighting illuminance may lead to improved detection, but such an increase also increases the risk of causing glare to other road users.

Being a pilot study, only a small sample was used - 10 participants for each experiment. Further work carried out to validate and extend these findings should employ a larger sample. The consistent findings for common conditions used in different experiments (Figure 8) suggest that the results are however reasonably robust. In further work, we would suggest the cyclist was freely cycling on the rollers rather than being held upright, 
thus to better simulate the cognitive demand of maintaining balance, and that the obstacle location is varied. We expect age to have a significant effect at low illuminance ${ }^{12,16}$ and therefore the young age of the sample used in the current work (18 years to 36 years old) should be extended to include also older people.

\section{Funding}

This work was carried out through support from EPSRC (EP/H050817, EP/M02900X/1) as part of the University of Sheffield MERLIN project and a scholarship from the government of Kuwait.

\section{References}

1 Caminada JF, van Bommel WJM. New lighting considerations for residential areas. International Lighting Review 1980; 3: 69-75.

2 Fotios S, Uttley J, Cheal C, Hara N. Using eye-tracking to identify pedestrians' critical visual tasks. Part 1. Dual task approach. Lighting Research and Technology 2015; 47: 133-148.

3 Fotios S, Uttley J, Yang B. Using eye-tracking to identify pedestrians' critical visual tasks. Part 2. Fixation on pedestrians. Lighting Research and Technology 2015; 47: 149-160.

4 Fotios S, Castleton HF. Lighting for cycling A review. Lighting Research and Technology First published online 6 October 2015. DOI: $10.1177 / 1477153515609391$.

5 Fotios S, Yang B, Uttley J. Observing other pedestrians: Investigating the typical distance and duration of fixation. Lighting Research and Technology 2015; 47: 548-564.

6 Igari D, Shimizu M, Fukuda R. Eye movements of elderly people while riding bicycles. Gerontechnology 2008; 7: 128.

7 Vansteenkiste P, Cardon G, D'Hondt E, Philippaerts R, Lenoir M. The visual control of bicycle steering: The effects of speed and path width. Accident Analysis and Prevention 2013; 51: 222-227.

8 Foulsham T, Walker E, Kingstone A. The where, what and when of gaze allocation in the lab and the natural environment. Vision Research 2011; 51: 1920-1931.

9 Vansteenkiste P, Zeuwts L, Cardon G, Philippaerts R, Lenoir M. The implications of low quality bicycle paths on gaze behavior of cyclists: A field test. Transportation Research Part F: Traffic Psychology and Behaviour 2014; 23: 81-87.

10 Inditsky B, Bodmann HW, Fleck HJ. Elements of visual performance. Lighting Research and Technology 1982; 14: 218-231.

11 Bodmann HW. Elements of photometry, brightness and visibility. Lighting Research and Technology 1992; 24: 29-42.

12 Uttley J, Fotios S, Cheal C. Effect of illuminance and spectrum on peripheral obstacle detection by pedestrians. Lighting Research and Technology First published online, 22 September 2015. DOI: 10.1177/ 1477153515602954.

13 Fotios S, Uttley J, Cheal C. Maintaining foveal fixation during a peripheral detection task. Lighting Research and Technology 2015. First published online 28 April 2015. DOI: $10.1177 / 1477153515583710$.

14 British Standards Institution. BS 5489-1:2013 Code of Practice for the Design of Road Lighting: Lighting of Roads and Public Amenity Areas. London: BSI, 2012.

15 Fotios S, Cheal C. Using obstacle detection to identify appropriate illuminances for lighting in residential roads. Lighting Research and Technology 2013; 45: 362-376.

16 Fotios SA, Cheal C. Obstacle detection: A pilot study investigating the effects of lamp type, illuminance and age. Lighting Research and Technology 2009; 41: 321-342.

17 Cai J-Y, Lo Y-C, Feng S-T, Sun C-C. Design of a highly efficient LED-based bicycle head lamp with additional ground illumination. Lighting Research and Technology 2014; 46: 747-753.

18 Rothman KJ. No adjustments are needed for multiple comparisons. Epidemiology 1990; 1: 43-46. 


\section{Appendix A. Obstacle luminances}

Table A1 Obstacle luminances in Experiment 1

\begin{tabular}{|c|c|c|c|c|}
\hline \multicolumn{2}{|l|}{ Test conditions } & \multicolumn{3}{|c|}{ Obstacle luminance } \\
\hline $\begin{array}{l}\text { Road } \\
\text { illuminance (lux) }\end{array}$ & $\begin{array}{l}\text { Cycle luminance } \\
\left(\mathrm{cd} / \mathrm{m}^{2}\right)\end{array}$ & $\begin{array}{l}\text { Side of } \\
\text { obstacle }\end{array}$ & $\begin{array}{l}\text { Top surface } \\
\text { of obstacle }\end{array}$ & $\begin{array}{l}\text { Floor immediately } \\
\text { in front of obstacle }\end{array}$ \\
\hline 0 & 0 & 0.001 & 0.001 & 0.001 \\
\hline 0 & 0.1 & 0.078 & 0.044 & 0.059 \\
\hline 0 & 0.316 & 0.248 & 0.141 & 0.206 \\
\hline 0 & 1.0 & 0.800 & 0.465 & 0.623 \\
\hline 0.2 & 0 & 0.013 & 0.016 & 0.017 \\
\hline 0.2 & 0.1 & 0.087 & 0.057 & 0.076 \\
\hline 0.2 & 0.316 & 0.261 & 0.158 & 0.219 \\
\hline 0.2 & 1.0 & 0.808 & 0.476 & 0.645 \\
\hline 2.0 & 0 & 0.078 & 0.122 & 0.124 \\
\hline 2.0 & 0.1 & 0.153 & 0.168 & 0.186 \\
\hline 2.0 & 0.316 & 0.328 & 0.266 & 0.329 \\
\hline 2.0 & 1.0 & 0.870 & 0.585 & 0.759 \\
\hline 20 & 0 & 0.756 & 1.223 & 1.228 \\
\hline 20 & 0.1 & 0.850 & 1.267 & 1.269 \\
\hline 20 & 0.316 & 1.028 & 1.367 & 1.429 \\
\hline 20 & 1.0 & 1.585 & 1.698 & 1.840 \\
\hline
\end{tabular}

Table A2 Obstacle luminances in Experiment 2

\begin{tabular}{|c|c|c|c|c|}
\hline \multicolumn{2}{|l|}{ Test conditions } & \multicolumn{3}{|c|}{ Obstacle luminance } \\
\hline $\begin{array}{l}\text { Road } \\
\text { illuminance (lux) }\end{array}$ & $\begin{array}{l}\text { Cycle lamp } \\
\text { position }\end{array}$ & $\begin{array}{l}\text { Side of } \\
\text { obstacle }\end{array}$ & $\begin{array}{l}\text { Top surface } \\
\text { of obstacle }\end{array}$ & $\begin{array}{l}\text { Floor immediately } \\
\text { in front of obstacle }\end{array}$ \\
\hline 0 & Helmet & 0.167 & 0.143 & 0.172 \\
\hline 0 & Handlebar & 0.248 & 0.141 & 0.206 \\
\hline 0 & Hub & 0.208 & 0.074 & 0.118 \\
\hline 0.2 & Helmet & 0.177 & 0.151 & 0.182 \\
\hline 0.2 & Handlebar & 0.261 & 0.158 & 0.219 \\
\hline 0.2 & Hub & 0.208 & 0.081 & 0.128 \\
\hline 2.0 & Helmet & 0.255 & 0.258 & 0.285 \\
\hline 2.0 & Handlebar & 0.328 & 0.122 & 0.329 \\
\hline 2.0 & Hub & 0.262 & 0.195 & 0.240 \\
\hline 20 & Helmet & 1.088 & 1.335 & 1.337 \\
\hline 20 & Handlebar & 1.028 & 1.367 & 1.429 \\
\hline 20 & Hub & 1.075 & 1.293 & 1.273 \\
\hline
\end{tabular}




\section{$602 S$ Fotios et al.}

Table A3 Obstacle luminances in Experiment 3

\begin{tabular}{|c|c|c|c|c|}
\hline \multicolumn{2}{|l|}{ Test conditions } & \multicolumn{3}{|c|}{ Obstacle luminance } \\
\hline $\begin{array}{l}\text { Road } \\
\text { illuminance (lux) }\end{array}$ & $\begin{array}{l}\text { Cycle luminance } \\
\left(\mathrm{cd} / \mathrm{m}^{2}\right)\end{array}$ & $\begin{array}{l}\text { Side of } \\
\text { obstacle }\end{array}$ & $\begin{array}{l}\text { Top surface } \\
\text { of obstacle }\end{array}$ & $\begin{array}{l}\text { Floor immediately } \\
\text { in front of obstacle }\end{array}$ \\
\hline 0 & 0 & 0.001 & 0.001 & 0.001 \\
\hline 0 & 0.1 & 0.066 & 0.026 & 0.039 \\
\hline 0 & 0.316 & 0.208 & 0.074 & 0.118 \\
\hline 0 & 1.0 & 0.637 & 0.226 & 0.401 \\
\hline 0.2 & 0 & 0.014 & 0.016 & 0.015 \\
\hline 0.2 & 0.1 & 0.068 & 0.036 & 0.050 \\
\hline 0.2 & 0.316 & 0.208 & 0.081 & 0.128 \\
\hline 0.2 & 1.0 & 0.621 & 0.221 & 0.360 \\
\hline 2.0 & 0 & 0.093 & 0.122 & 0.123 \\
\hline 2.0 & 0.1 & 0.144 & 0.143 & 0.156 \\
\hline 2.0 & 0.316 & 0.262 & 0.195 & 0.240 \\
\hline 2.0 & 1.0 & 0.632 & 0.359 & 0.521 \\
\hline 20 & 0 & 0.918 & 1.214 & 1.207 \\
\hline 20 & 0.1 & 0.960 & 1.238 & 1.194 \\
\hline 20 & 0.316 & 1.075 & 1.293 & 1.273 \\
\hline 20 & 1.0 & 1.439 & 1.445 & 1.609 \\
\hline
\end{tabular}

